\title{
MicroRNA-486-5p inhibits the growth of human hypertrophic scar fibroblasts by regulating Smad2 expression
}

\author{
YINGYING SHI, LUPING WANG, PIJUN YU, YI LIU and WEI CHEN \\ Department of Decorative Plastic Surgery, The Eighth People's Hospital of Shanghai, \\ Jiangsu University, Shanghai 200233, P.R. China
}

Received April 9, 2018; Accepted November 5, 2018

DOI: $10.3892 / \mathrm{mmr} .2019 .10186$

\begin{abstract}
The aim of the current study was to investigate the expression and role of microRNA-486-5p (miR-486-5p) in hypertrophic scar (HS) formation, and to examine the associated mechanisms. First, miR-486-5p expression was detected in HS tissues and human hypertrophic scar fibroblasts (hHSFs) by reverse transcription-quantitative polymerase chain reaction. Target genes of miR-486-5p were predicted using TargetScan and verified by dual-luciferase reporter assays. To investigate the role of miR-486-5p in HS formation, miR-486-5p was overexpressed in hHSFs through transfection with miR-486-5p mimics. MTT, cell apoptosis and cell cycle assays were preformed to investigate the proliferation, cell apoptosis and cell cycle distribution of hHSFs, respectively. Additionally, protein expression was measured by western blot analysis. The results demonstrated that miR-486-5p expression was significantly decreased in HS tissues and cells. Mothers against decapentaplegic homolog (Smad)2 was a target gene of miR-486-5p, and it was negatively regulated by miR-486-5p. It was also found that $\mathrm{Smad} 2$ expression was significantly increased in HS tissues and cells. Further analysis indicated that miR-486-5p mimic transfection inhibited the proliferation, induced cell apoptosis and increased G1/S phase arrest in hHSFs. Furthermore, the expression of cyclin-dependent kinase (CDK)2, CDK4 and apoptosis regulator Bcl-2 was repressed, while apoptosis regulator BAX expression was enhanced by miR-486-5p mimic transfection. Notably, the effects of miR-486-5p mimic on hHSFs were significantly eliminated by Smad2 plasmid transfection. Taken together, these results demonstrated that miR-486-5p inhibited the proliferation, induced apoptosis and increased G1/S phase arrest of hHSFs by targeting Smad2. miR-486-5p may be a promising therapeutic target for HS management.
\end{abstract}

Correspondence to: Dr Wei Chen, Department of Decorative Plastic Surgery, The Eighth People's Hospital of Shanghai, Jiangsu University, 8 Caobao Road, Shanghai 200233, P.R. China

E-mail: chenwei201717@163.com

Key words: hypertrophic scar, microRNA-486-5p, Smad2, cell proliferation, apoptosis, cell cycle

\section{Introduction}

Scars are traces of wound healing and are the end result of tissue repair. Large scars, which may be caused by burns, lacerations, surgery and vaccination, affect the patient's quality of life both physically and psychologically (1). Excessive scarring may occur due to pain, itching and contracture (1). Severe trauma, inappropriate wound closure and occasionally standard surgery may lead to the formation of atypical raised scars, termed hypertrophic scars (HS) (2). HS is characterized by excessive growth of dense fibrous tissues (3-5). At present, there are many methods for treating HS, including surgery, steroid injection and laser surgery, but the effects remain unsatisfactory (6). Recently, the molecular mechanisms of HS pathogenesis have been unraveled, thus providing new promise for the use of gene therapy to treat HS. Many genes that regulate extracellular matrix deposition and fibroblast hyperplasia are involved in the development and progression of HS. Increasing evidence has indicated that microRNAs (miRNAs/miRs) are involved in the progression of HS (7-10).

miRNAs, a family of small ( $22 \mathrm{nt})$, non-coding, single stranded and highly conserved RNAs, negatively regulate the expression of target genes during various cellular events, including proliferation, apoptosis and differentiation, through binding to the 3'untranslated region (UTR) of target genes (11-14). Dysregulation of miRNA expression is involved in various pathophysiological processes, including wound healing, and is closely associated with the formation of HS (7-10). MiR-486-5p, a well-studied miRNA in cancer, has been reported as a tumor inhibitor in a variety of cancer types, including breast, colorectal, lung and gastric cancer (15-18). miR-486-5p serves an important role in the regulation of cell growth $(15,19)$, and fibroblast hyperplasia is one of the main features of HS formation (20). Therefore, it was hypothesized that miR-486-5p may be involved in HS pathology. To the best of our knowledge, the expression and functional role of miR-486-5p in HS remains unknown. Thus, their relationship was investigated in the current study.

A large number of studies have demonstrated a key role for transforming growth factor- $\beta$ (TGF- $\beta$ ) in HS formation (21). TGF- $\beta$ signaling involves mothers against decapentaplegic homolog (Smad) proteins (22). During HS progression, Smad2 upregulation and increased TGF- $\beta$ production often occur. Silencing of Smad 2 gene expression inhibits the TGF- $\beta$ 
signaling pathway and consequently reduces HS formation (23). In the present study, Smad2 was predicted as a potential target gene of miR486-5p by bioinformatics software, suggesting a role of the $\mathrm{miR} 486-5 \mathrm{p} / \mathrm{Smad} 2$ axis in HS formation.

In the present study, the differential expression of miR-486-5p in HS tissues and cells was determined. Smad2, one of the important members of the TGF- $\beta$ signaling pathway (24), was identified as a direct target of miR486-5p and was upregulated in HS. Smad2 was negatively regulated by miR-486-5p in human hypertrophic scar fibroblasts (hHSFs). Although the relationship between miR-486-5p and Smad2 in pulmonary fibrosis and lens epithelial cells has been studied $(25,26)$, its role in HS is unclear. The present study demonstrated that miR-486-5p inhibited the proliferation, increased the apoptosis and induced G1/S phase arrest of hHSFs by targeting Smad2. Hyperplasia of fibroblasts is one of the main features of HS formation (20). Therefore, the current study indicated that miR-486-5p may be a promising therapeutic target for HS management.

\section{Materials and methods}

Clinical samples. A total of $60 \mathrm{HS}$ (during scar excision; 32-57 years old; gender ratio, 1:1) and 60 normal control skin (NCS; during auto-skin grafting; 29-54 years old; gender ratio, 1:1) tissues were collected from the thigh during biopsies at The Eighth People's Hospital of Shanghai between February 2015 and September 2017. All tissues were immediately stored in liquid nitrogen until use. The present study was approved by the Ethics Committee of The Eighth People's Hospital of Shanghai. Informed consent was obtained from each patient.

Cell culture. hHSFs (27) were obtained from Shanghai Guandao Biological Engineering Co., Ltd. (cat no. C0618; Shanghai, China; sgdbio.chemdrug.com), and human embryonic skin fibroblasts CCC-ESF-1 (; https://www.biomart. cn/infosupply/30393402.htm?from=search_1) were purchased from Shanghai Zibo Biological Technology Co., Ltd. (cat no. YB-ATCC-3084; Shanghai, China; shybio.biomart. $\mathrm{cn})$. Both cell lines were cultured in RPMI-1640 medium supplemented with $10 \%$ fetal bovine serum (both Invitrogen; Thermo Fisher Scientific, Inc., Waltham, MA, USA), 10,000 units $/ \mathrm{ml}$ penicillin, and $10,000 \mu \mathrm{g} / \mathrm{ml}$ streptomycin. Prior to cell transfection, cells were incubated at $37^{\circ} \mathrm{C}$ with $5 \% \mathrm{CO}_{2}$ for $24 \mathrm{~h}$ to reach $70-80 \%$ confluence.

Cell transfection. miR-486-5p mimics (mimic; sense: CGG GGCAGCUCAGUACAGGAUU; anti-sense: UCCUGUACU GAGCUGCCCCGAG) and mimic-control (mimic-c; sense: UUCUCCGAACGUGUCACUUTT; anti-sense: ACGUGA CACGUUCGGAGAAATT) were obtained from Guangzhou RiboBio Co., Ltd. (Guangzhou, China). control-plasmid (control-p; cat. no. sc-108083) and Smad2-plasmid (plasmid; cat. no. sc-421525-ACT) were purchased from Santa Cruz Biotechnology, Inc. (Santa Cruz, CA, USA). To perform cell transfection, Lipofectamine ${ }^{\circledR}$ 3,000 (Invitrogen; Thermo Fisher Scientific, Inc., Waltham, MA, USA) was used according to the manufacturer's instructions. Cells were transfected with $50 \mathrm{nM}$ mimic, $50 \mathrm{nM}$ mimic-c, $50 \mathrm{nM}$ mimic $+2 \mu 1$ control-p or $50 \mathrm{nM}$ mimic $+2 \mu 1$ plasmid. Untreated cells were used as the control group (control). hHSFs cells were harvested for subsequent experimentation $48 \mathrm{~h}$ after cell transfection.

Western blot analysis. Total protein from hHSFs was extracted using radioimmunoprecipitation assay lysis buffer (Beyotime Institute of Biotechnology, Haimen, China) $48 \mathrm{~h}$ after transfection. A bicinchoninic acid protein assay was performed to determine the quality of the protein samples. Equal amount of protein (30 $\mu \mathrm{g}$ per lane) were separated by SDS-PAGE (12\% gel) and transferred to polyvinylidene difluoride membranes. Membranes were blocked with 5\% skimmed milk in Tris buffered saline with $0.1 \%$ Tween-20 at room temperature for $1.5 \mathrm{~h}$, followed by incubation with primary antibodies (Cell Signaling Technology, Inc., Danvers, MA, USA) against Smad2 (cat. no. 5339; 1:1,000), cyclin-dependent kinase (CDK)2 (cat. no. 2546; 1:1,000), CDK4 (cat. no. 12790; 1:1,000), apoptosis regulator $\mathrm{Bcl}-2$ (Bcl-2; cat. no. 4223; 1:1,000), apoptosis regulator BAX (Bax; cat. no. 5023; 1:1,000) and $\beta$-actin (no. $4970 ; 1: 5,000$ ) at $4^{\circ} \mathrm{C}$ overnight. Subsequently, the membranes were incubated with anti-rabbit immunoglobulin $\mathrm{G}$ horseradish peroxidase-conjugated secondary antibody (cat no. 7074; 1:2,000; Cell Signaling Technology, Inc.) at room temperature for $2 \mathrm{~h}$. Finally, protein bands were visualized with an enhanced chemiluminescence detection system (Applygen Technologies, Inc., Beijing, China). ImageJ 1.38X (National Institutes of Health, Bethesda, MD, USA) was used to perform densitometry.

Reverse transcription-quantitative polymerase chain reaction $(R T-q P C R)$. TRIzol reagent (Invitrogen; Thermo Fisher Scientific, Inc.) was used to extract total RNA from cells and tissues. Reverse transcription of RNA into cDNA was performed using miScript Reverse Transcription kit (Qiagen $\mathrm{GmbH}$, Hilden, Germany) according to the manufacturer's instructions. RT-qPCR was conducted using the SYBR Premix Ex Taq $^{\mathrm{TM}}$ II (TliRNaseH Plus) kit (Takara Bio, Inc., Otsu, Japan) according to the manufacturer's protocol. U6 and GAPDH were used as internal control for miRNA and mRNA, respectively. Primer sequences for PCR were: GAPDH forward, 5'CTTTGGTATCGTGGAAGGACTC3'; reverse, 5'GTAGAGGCAGGGATGATGTTCT3'; U6 forward, 5'GCT TCGGCAGCACATATACTAAAAT3'; reverse, 5'CGCTTC ACGAATTTGCGTGTCAT3'; miR-486-5p forward, 5'ACA CTCCAGCTGGGTCCTGTACTGAGCTGCCC3'; reverse, 5'CTCAACTGGTGTCGTGGAGTCGGCAATTCAGTT GAGCCCCGAG3'; Smad2 forward, 5'CGTCCATCTTGC CATTCACG3'; reverse, 5'CTCAAGCTCATCTAATCGTC CTG3'. Relative gene expression was analyzed using the $2^{-\Delta \Delta C q}$ method (28).

MTT assay. hHSFs ( $5 \times 10^{3}$ cells/well) were seeded into 96-well plates and cultured at $37^{\circ} \mathrm{C}$ with $5 \% \mathrm{CO}_{2}$. MTT solution $(20 \mu \mathrm{l})$ was added into each well $48 \mathrm{~h}$ after transfection, and the plates were incubated at $37^{\circ} \mathrm{C}$ for another $4 \mathrm{~h}$. DMSO was used to dissolve the purple formazan. Next, optical density at $570 \mathrm{~nm}$ of each sample was detected using a microplate reader.

Cell apoptosis assay. Following transfection for $48 \mathrm{~h}$, hHSFs were subjected to a cell apoptosis assay. hHSFs $\left(10^{6}\right)$ were dyed with Annexin V/propidium iodide (PI) using an apoptosis 

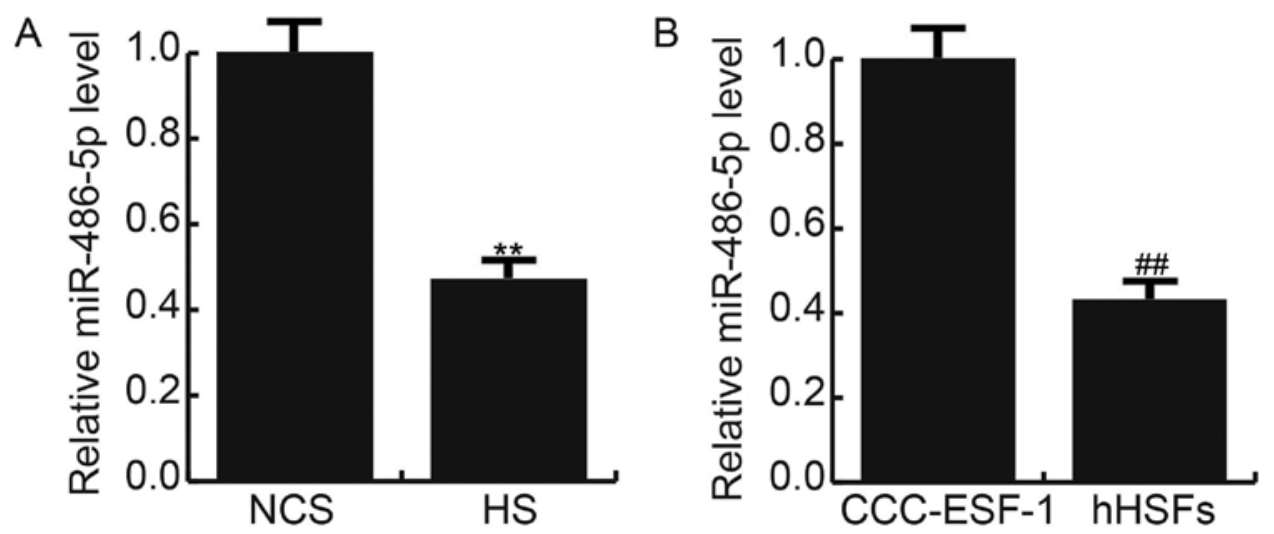

Figure 1. miR-486-5p expression is downregulated in HS tissues and cells. Relative miR-486-5p expression was determined in (A) HS and paired NCS tissues, as well as (B) CCC-ESF-1 cells and hHSFs. Data are presented as the mean \pm standard deviation. ${ }^{* *} \mathrm{P}<0.01 \mathrm{vs.} \mathrm{NCS;}{ }^{\# \#} \mathrm{P}<0.01$ vs. CCC-ESF-1. miR, microRNA; HS, hypertrophic scar; NCS, normal control skin; hHSFs, human HS fibroblasts.

detection kit (cat. no. 556547; BD Biosciences, Franklin Lakes, NJ, USA) for $15 \mathrm{~min}$ at room temperature in the dark, according to the manufacturer's protocol. At last, cell apoptosis was analyzed by flow cytometry (BD Biosciences, Franklin Lakes, NJ, USA), and data were analyzed using WinMDI software (version 2.5; Purdue University Cytometry Laboratories; www.cyto.purdue. edu/flowcyt/software/Catalog.htm).

Cell cycle assay. Transfected hHSFs were seeded in six-well plates $\left(2 \times 10^{5}\right.$ cells/well) and cultured for $24 \mathrm{~h}$ at $37^{\circ} \mathrm{C}$. Following treatment with $0.3 \mu \mathrm{M}$ nocodazole (Sigma-Aldrich; Merck $\mathrm{KGaA}$, Darmstadt, Germany) at $4^{\circ} \mathrm{C}$ for $24 \mathrm{~h}$, the cells were collected, washed with PBS solution, and fixed with cold 70\% ethanol overnight at $-20^{\circ} \mathrm{C}$. Subsequently, cells were incubated with $10 \mathrm{mg} / \mathrm{ml} \mathrm{RNase} \mathrm{A,} 400 \mathrm{mg} / \mathrm{ml}$ PI, and $0.1 \%$ Triton X at $37^{\circ} \mathrm{C}$ for $15 \mathrm{~min}$. Finally, cell cycle distribution of hHSFs were analyzed by flow cytometry, and the percentage of cells within each phase of the cell cycle was determined using ModFit LT version 4.1 (Verity Software House, Inc., Topsham, ME, USA).

Dual-luciferase reporter assay. TargetScanHuman 7.1 (www. targetscan.org/vert_71) was used to predict the target genes of miR-486-5p, which indicated that Smad2 was potential target of miR-486-5p. The dual-luciferase reporter vector pmiR-RB-REPORT ${ }^{\text {тм }}$ (Guangzhou RiboBio Co., Ltd., Guangzhou, China) was used in current study. To confirm that miR-486-5p directly bound to the 3'-UTR of Smad2, the vectors named Smad2-3'-UTR-WT and Smad2-3'-UTR-MUT with the wild-type and mutated 3'-UTR of Smad2 mRNA were constructed. Then, hHSFs were co-transfected with Smad2-3'UTR-WT or Smad2-3'UTR-MUT, and mimic or mimic-c, using Lipofectamine ${ }^{\circledR} 3000$ (Invitrogen; Thermo Fisher Scientific, Inc.) at $37^{\circ} \mathrm{C}$ for $48 \mathrm{~h}$. Luciferase activity was subsequently determined using a dual luciferase reporter assay system (Promega Corporation, Madison, WI, USA) according to the manufacturer's protocols, and was normalized to Renilla luciferase activity.

Statistical analysis. Data were presented as the mean \pm standard deviation of at least three experimental repeats. SPSS software version 18.0 (IBM Corp., Armonk, NY, USA) was used to perform the statistical analysis. For statistical comparisons,
A

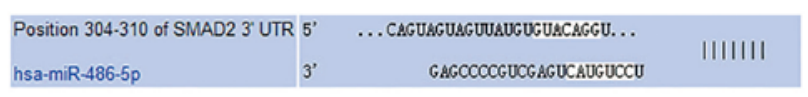

B

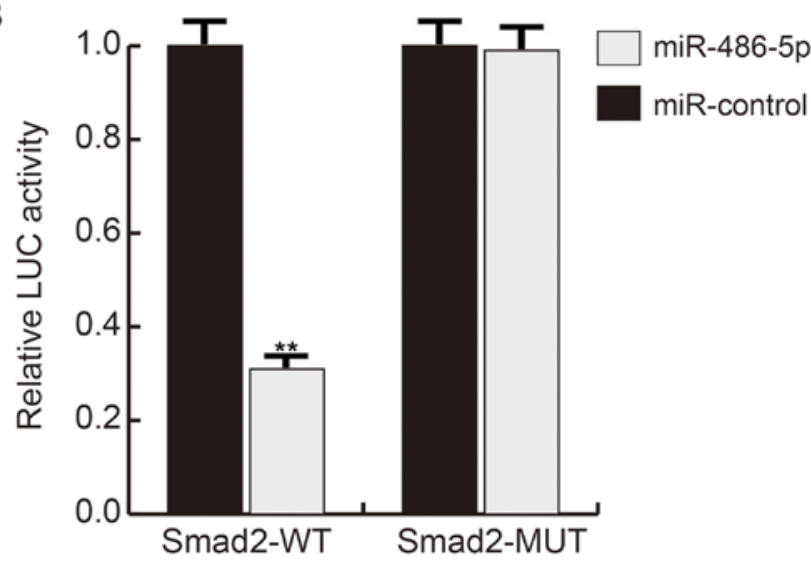

Figure 2. Smad2 is a target gene of miR-486-5p. (A) TargetScan was used to predict the interaction between miR-486-5p and the 3'-UTR of Smad2. (B) Luciferase activity was measured with a dual-luciferase reporter assay. Data are presented as the mean \pm standard deviation. ${ }^{* *} \mathrm{P}<0.01 \mathrm{vs.} \mathrm{miR-control}$. Smad2, mothers against decapentaplegic homolog 2; miR, microRNA; MUT, mutant; UTR, untranslated region; WT, wild-type; mimic-c, cells transfected with mimic-control; mimic, cells transfected with miR-486-5p mimics; LUC, luciferase.

one-way analysis of variance followed by Tukey's post-hoc test, or Student's t-test were used. $\mathrm{P}<0.05$ was considered to indicate a statistically significant difference.

\section{Results}

miR-486-5p expression is decreased in HS tissues and hHSFs. As presented in Fig. 1, it was shown that compared with the NCS tissues, the RNA expression of miR-486-5p was significantly decreased in HS tissues (Fig. 1A). miR-486-5p expression was also detected in CCC-ESF-1 cells and hHSFs, which showed that the RNA expression of miR-486-5p was significantly lower in hHSFs, compared with CCC-ESF-1 cells (Fig. 1B).

miR-486-5p directly targets Smad2. TargetScan software suggested that miR-486-5p may bind to the 3'-UTR of Smad2 

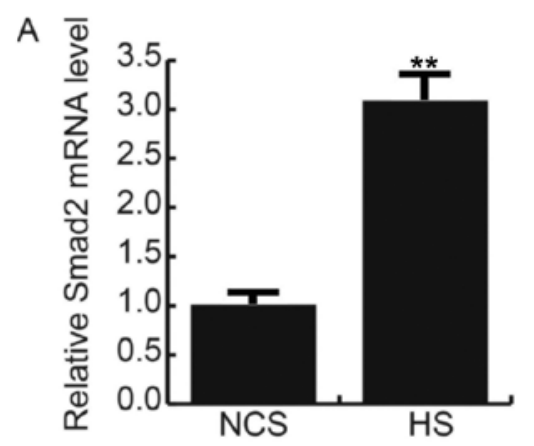

C

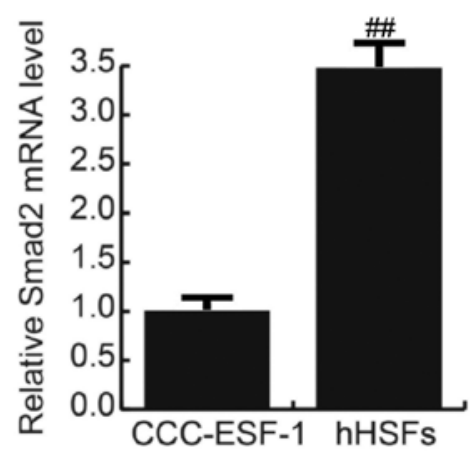

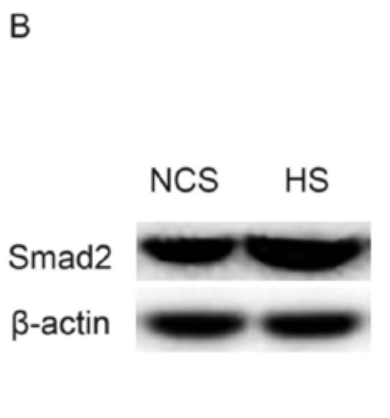

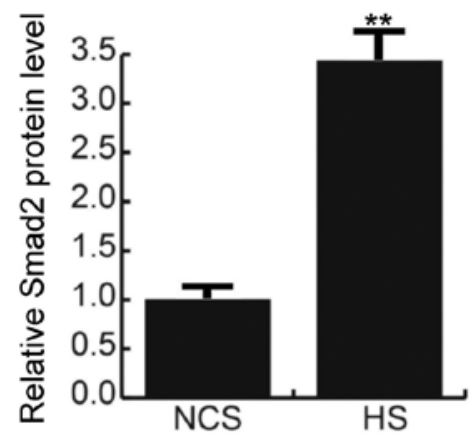

D

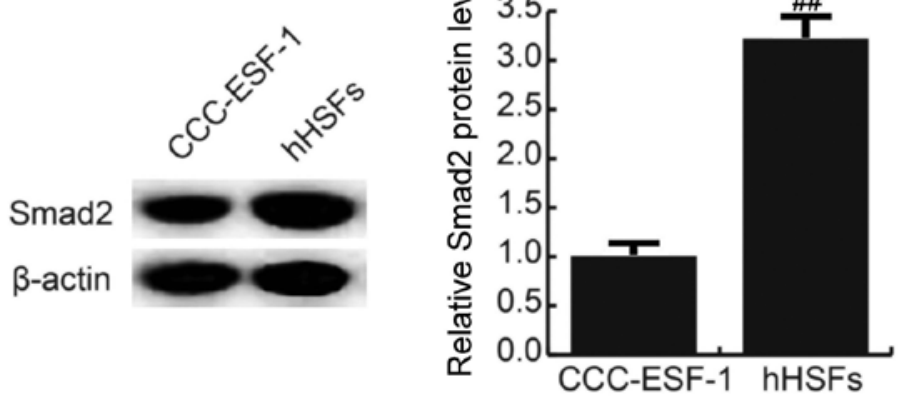

Figure 3. Smad2 expression is upregulated in HS tissues and cells. (A) Smad2 mRNA and (B) protein expression in HS and paired NCS tissues. (C) Smad2 mRNA and (D) protein expression in CCC-ESF-1 cells and hHSFs. Data are presented as the mean \pm standard deviation. ${ }^{* *} \mathrm{P}<0.01$ vs. NCS; ${ }^{\# \#} \mathrm{P}<0.01$ vs. CCC-ESF-1. miR, microRNA; HS, hypertrophic scar; NCS, normal control skin; hHSFs, human HS fibroblasts; Smad2, mothers against decapentaplegic homolog 2 .

(Fig. 2A). To confirm the binding site, a dual luciferase reporter assay was performed, which indicated that compared with the control group, mimic transfection significantly reduced the luciferase activity in hHSFs transfected with Smad2-WT, while no significant difference was observed in cells co-transfected with Smad2-MUT and mimic or mimic-c, demonstrating that miR-486-5p directly targets $\operatorname{Smad} 2$ (Fig. 2B).

Smad2 expression is increased in HS tissues and hHSFs. As presented in Fig. 3, it was found that compared with the NCS tissues, the mRNA (Fig. 3A) and protein (Fig. 3B) expression of Smad2 was significantly increased in HS tissues. The mRNA (Fig. 3C) and protein (Fig. 3D) expression 1 of Smad2 was also significantly enhanced in hHSFs, compared with the CCC-ESF-1 cells.

miR-486-5p transfection inhibits cell proliferation. To investigate the role of miR-486-5p in hHSFs, miR-486-5p mimic, mimic-c, control-p, Smad2-plasmid or mimic+plasmid were transfected into hHSFs. The transfection efficiency was examined by RT-qPCR $48 \mathrm{~h}$ after transfection. miR-486-5p expression was significantly increased in hHSFs transfected with miR-486-5p mimic compared with the mimic-c (Fig. 4A), and Smad2-plasmid markedly enhanced Smad2 mRNA expression in hHSFs, compared with the control-p group (Fig. 4B). In addition, the protein (Fig. 4C) and mRNA (Fig. 4D) expression of Smad2 in each group was detected. Cell proliferation was measured using a MTT assay, and the results revealed that mimic transfection significantly inhibited the proliferation of hHSFs, compared with the mimic-c group, and this inhibition was prevented by plasmid transfection (Fig. 4E).

miR-486-5p transfection induces cell apoptosis and G1/S phase arrest in $h H S F s$. Flow cytometry analysis revealed that the number of apoptotic cells increased in hHSFs transfected with miR-486-5p mimic, compared with the control group, and this increase was reduced by plasmid co-transfection (Fig. 5A and B). Furthermore, the expression of pro-apoptotic protein Bax and anti-apoptotic protein Bcl-2 was measured by western blotting. As expected, miR-486-5p mimic significantly increased Bax and decreased Bcl-2 protein expression. These alterations were eliminated by plasmid overexpression (Fig. 5C).

Next, it was determined whether miR-486-5p affected the cell cycle distribution of hHSFs. As presented in Fig. 6A, a marked accumulation of hHSFs in G1/S phase was observed in mimic transfected group, suggesting that miR-486-5p induced G1/S phase arrest in hHSFs. In addition, cell cycle-associated genes expression was determined. It was demonstrated that CDK2 and CDK4 were significantly downregulated in hHSFs transfected with miR-486-5p mimics, compared with the control group; plasmid co-transfection reduced this decrease (Fig. 6B).

\section{Discussion}

In the present study, it was determined that miR-486-5p inhibited hHSF proliferation, induced apoptosis and increased G1/S phase arrest by repressing $\operatorname{Smad} 2$ expression. It was revealed 
A

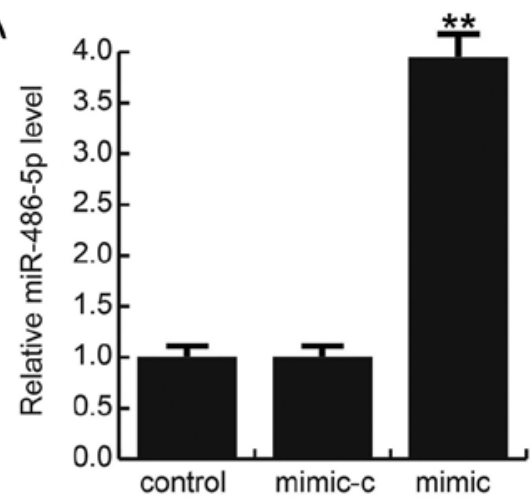

C
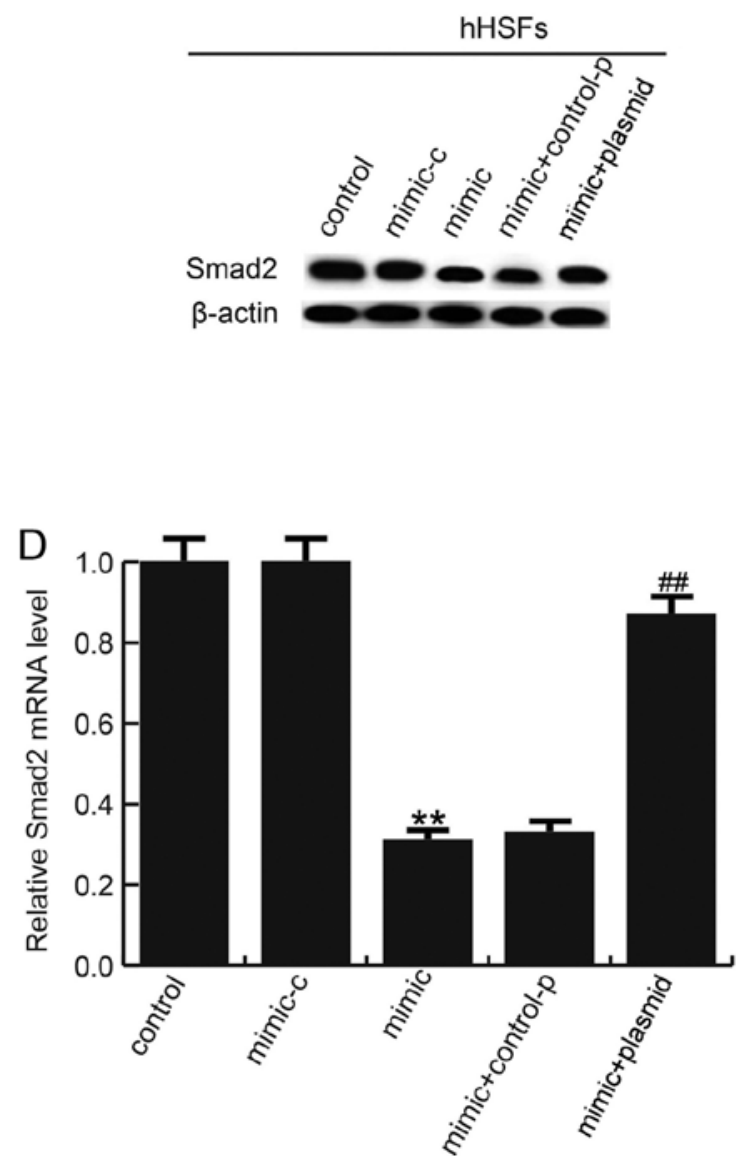

B
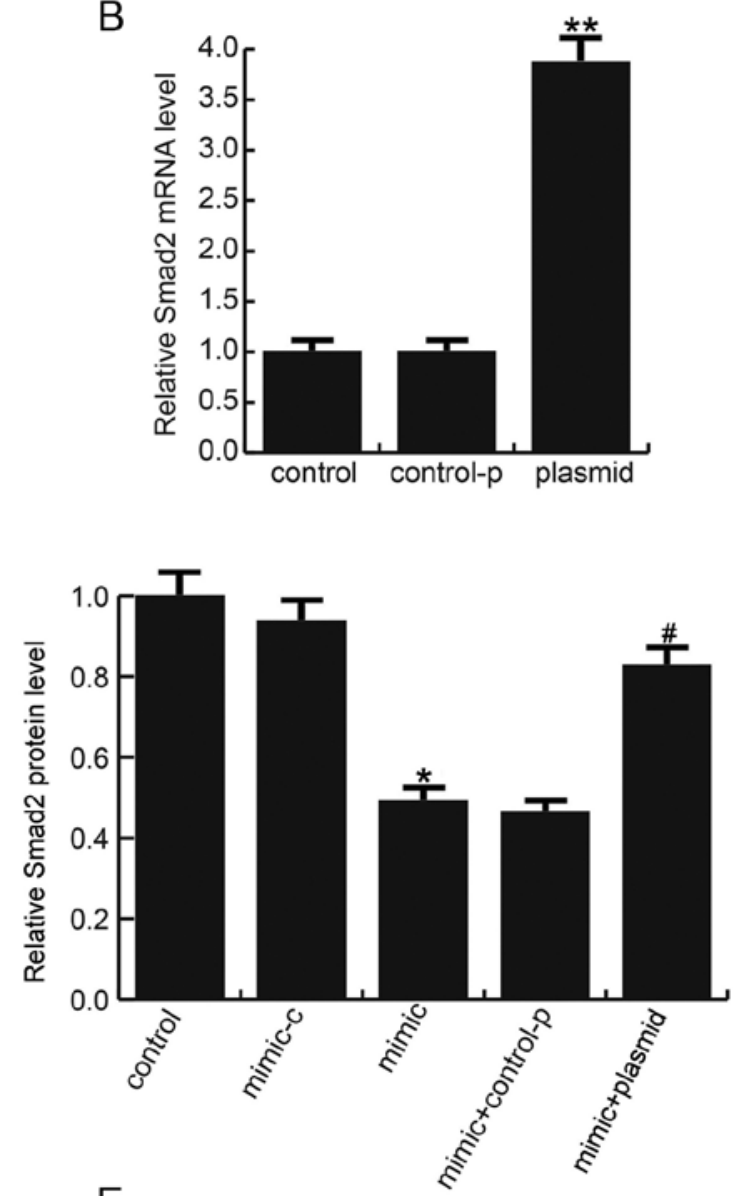

E

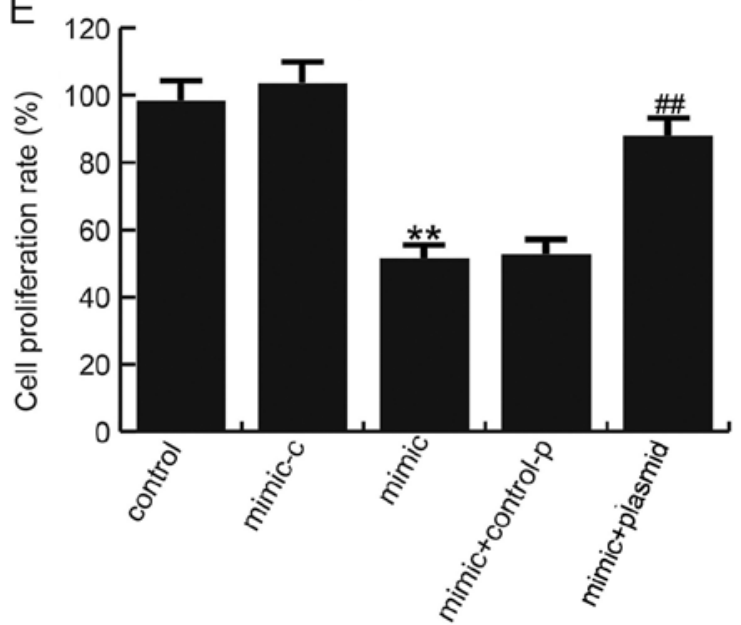

Figure 4. miR-486-5p decreases hHSF proliferation. Transfection efficiency of (A) miR-486-5p mimics and (B) Smad2 plasmid was examined by RT-qPCR (C) Smad protein and (D) mRNA expression was determined in each group by western blotting and RT-qPCR, respectively. (E) Cell proliferation was detected with MTT assays. Data are presented as the mean \pm standard deviation; ${ }^{* * *} \mathrm{P}<0.01$ vs. control; ${ }^{* \#} \mathrm{P}<0.01$ vs. mimic. OD, optical density. Smad2, mothers against decapentaplegic homolog 2; hHSFs, human hypertrophic scar fibroblasts; RT-qPCR, reverse transcription-quantitative polymerase chain reaction; miR, microRNA; control, untreated cells; mimic-c, cells transfected with mimic-control; mimic, cells transfected with miR-486-5p mimics; control-p: cells transfected with control-plasmid; plasmid, cells transfected with Smad2-plasmid.

that the $\mathrm{miR}-486-5 \mathrm{p} / \mathrm{Smad} 2$ axis may act as a potential therapeutic target for the treatment of HS.

Normal and pathological wound healing processes are complex $(29,30)$. Histologically, HS is characterized by excessive fibroblast and mast cell proliferation, accompanied by excessive extracellular matrix accumulation (20). Unfortunately, the precise pathogenesis of HS remains unclear and current treatments for HS are limited (31). It has been suggested that abnormal miRNA expression has critical function in the progression of skin fibrosis (32). Several studies have demonstrated the anti-cancer or tumor promoting effects of miR-486-5p in various tumors: For example, miR-486-5p may be involved in prostate cancer progression by negatively regulating several tumor suppressor pathways (33). miR-486-5p may also promote the development of hepatocellular carcinoma via negative regulation of serine/threonine-protein kinase NEK2 


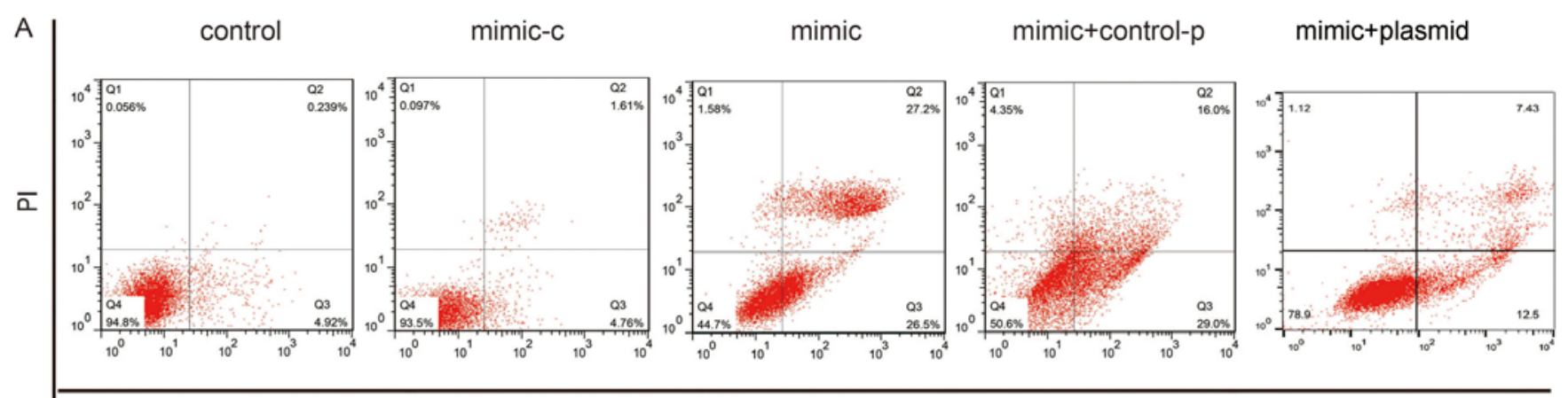

FITC

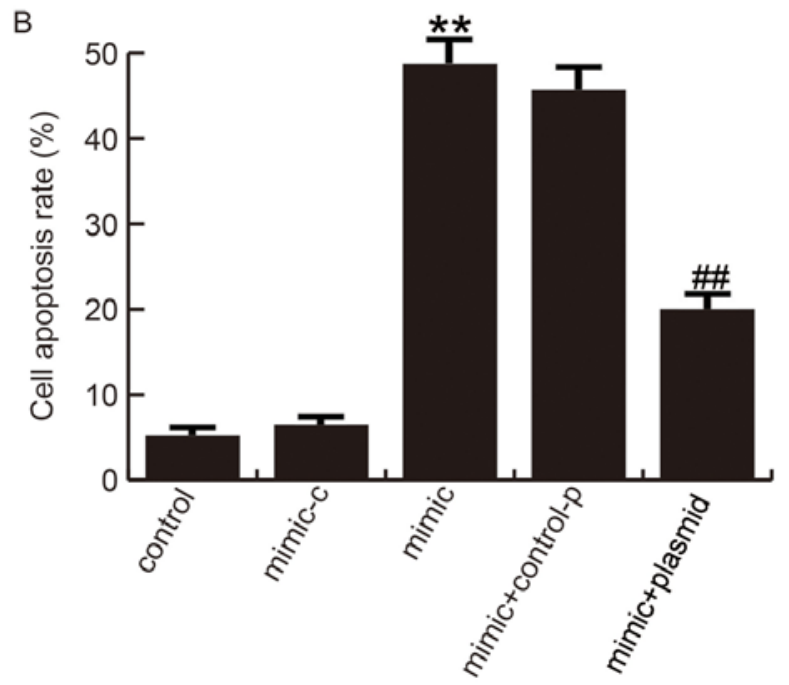

C

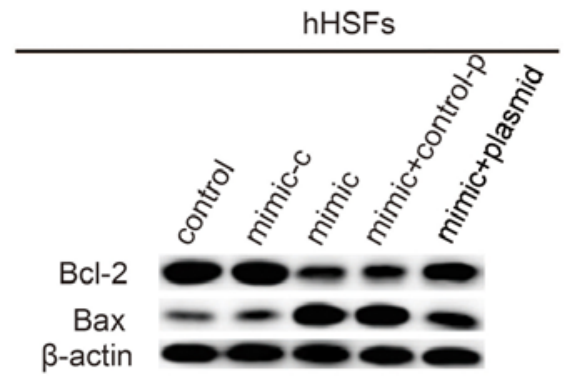

Figure 5. miR-486-5p increases hHSF apoptosis. (A) At $48 \mathrm{~h}$ post-transfection, flow cytometry was performed and (B) the results were quantified to assess the effect of miR-486-5p on hHSF apoptosis. (C) The effects of miR-486-5p on Bcl-2 and Bax protein expression were analyzed by western blotting. Data are presented as the mean \pm standard deviation. ${ }^{* *} \mathrm{P}<0.01$ vs. control; ${ }^{\# \#} \mathrm{P}<0.01$ vs. mimic. miR, microRNA; hHSFs, human hypertrophic scar fibroblasts; PI, propidium iodide; FITC, fluorescein isothiocyanate; Bcl-2, apoptosis regulator Bcl-2; Bax, apoptosis regulator BAX; control, untreated cells; mimic-c, cells transfected with mimic-control; mimic, cells transfected with miR-486-5p mimics; control-p: Cells transfected with control-plasmid; plasmid, cells transfected with Smad2-plasmid.

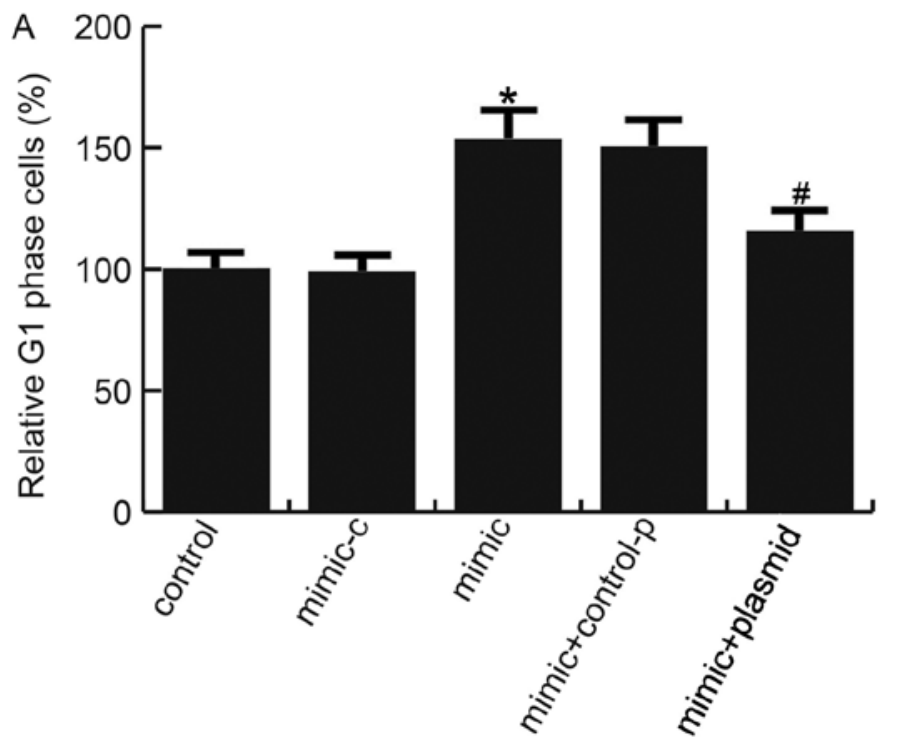

B

Figure 6. Effects of miR-486-5p on hHSF cell cycle distribution. (A) At $48 \mathrm{~h}$ post-transfection, flow cytometry was used to assess the effect of miR-486-5p on hHSF cell cycle distribution. (B) Effects of miR-486-5p on CDK2 and CDK4 protein expression was analyzed by western blotting. Data are presented as the mean \pm standard deviation. ${ }^{*} \mathrm{P}<0.01$ vs. control; ${ }^{~} \mathrm{P}<0.01$ vs. mimic. miR, microRNA; hHSFs, human hypertrophic scar fibroblasts; CDK, cyclin-dependent kinase; control, untreated cells; mimic-c, cells transfected with mimic-control; mimic, cells transfected with miR-486-5p mimics; control-p: Cells transfected with control-plasmid; plasmid, cells transfected with Smad2-plasmid. 
expression (34). Youness et al (35) reported that miR-486-5p acts as a tumor suppressor in hepatocellular carcinoma through the repression of essential proteins involved in insulin-like growth factor (IGF) signaling, including IGF-1 receptor and its downstream mediators mammalian target of rapamycin, signal transducer and activator of transcription (STAT) 3 and proto-oncogene c-Myc. Furthermore, transfer of miR-486-5p from human endothelial colony forming cell-derived exosomes may attenuate ischemic kidney injury (36). miR-486-5p may suppress TGF- $\beta 2$-induced proliferation of lens epithelial cells (26), as well as lung fibrosis $(37,38)$. These reports indicate that miR-486-5p may have a potential therapeutic effect on HS. Therefore, the present study was conducted.

First, the RNA expression of miR-486-5p was detected in HS and NCS tissues, as well as in hHSFs and human embryonic skin fibroblasts (CCC-ESF-1). The results confirmed that miR-486-5p expression was significantly decreased in HS tissues and cells. Then, it was determined that $\operatorname{Smad} 2$ was direct target of miR-486-5p and was negatively regulated by miR-486-5p in hHSFs. It was also demonstrated that Smad2 was significantly upregulated in HS tissues and cells. Smad proteins are signal transducers and transcriptional modulators that mediate multiple signaling pathways. Smad 2 mediates TGF- $\beta$ signaling, thus regulating multiple cellular processes, such as cell proliferation, apoptosis and differentiation $(37,38)$. The effects of miR-486-5p on hHSF proliferation was subsequently examined, by transfecting hHSFs with miR-486-5p mimic. The findings suggested that miR-486-5p overexpression inhibited hHSF proliferation, induced apoptosis and increased G1/S phase arrest. Furthermore, it was revealed that CDK2, CDK4 and Bcl-2 expression was repressed, and Bax expression was enhanced by miR-486-5p mimic in hHSFs. In addition, the effects of miR-486-5p on hHSFs were eliminated by $\mathrm{Smad} 2$ overexpression.

To the best of the authors' knowledge, this was the first study to reveal that miR-486-5p inhibited hHSF proliferation, promoted apoptosis and induced G1/S phase arrest through the regulation of cell apoptosis and cell cycle-associated genes via Smad2. Thus, miR-486-5p may be a useful target for the treatment of HS.

\section{Acknowledgements}

Not applicable.

\section{Funding}

No funding was received.

\section{Availability of data and materials}

All data sets used and/or generated during the current study are available from the corresponding author on reasonable request.

\section{Authors' contributions}

YS designed the study. YS, LW and PY analyzed the data. YL and WC analyzed the data and prepared the manuscript. All authors read and approved the final manuscript.

\section{Ethics approval and consent to participate}

The present study was approved by the Ethics Committee of The Eighth People's Hospital of Shanghai. Informed consent was obtained from each patient.

\section{Patient consent for publication}

Not applicable.

\section{Competing interests}

The authors declare that they have no competing interests.

\section{References}

1. Tyack ZF, Pegg S and Ziviani J: Postburn dyspigmentation: Its assessment, management, and relationship to scarring-a review of the literature. J Burn Care Rehabil 18: 435-440, 1997.

2. Gauglitz GG, Korting HC, Pavicic T, Ruzicka T and Jeschke MG: Hypertrophic scarring and keloids: Pathomechanisms and current and emerging treatment strategies. Mol Med 17: 113-125, 2011.

3. Aarabi S, Bhatt K A, Shi Y, Paterno J, Chang EI, Loh SA Holmes JW, Longaker MT, Yee H and Gurtner GC: Mechanical load initiates hypertrophic scar formation through decreased cellular apoptosis. FASEB J 21: 3250-3261, 2007.

4. van der Veer WM, Bloemen MC, Ulrich MM, Molema G, van Zuijlen PP, Middelkoop E and Niessen FB: Potential cellular and molecular causes of hypertrophic scar formation. Burns 35: 15-29, 2009.

5. Younai S, Nichter LS, Wellisz T, Reinisch J, Nimni ME and Tuan TL: Modulation of collagen synthesis by transforming growth factor-beta in keloid and hypertrophic scar fibroblasts. Ann Plast Surg 33: 148-154, 1994.

6. Zuccaro J, Ziolkowski $\mathrm{N}$ and Fish J: A systematic review of the effectiveness of laser therapy for hypertrophic burn scars. Clin Plast Surg 44: 767-779, 2017.

7. Li P, He QY and Luo CQ: Overexpression of miR-200b inhibits the cell proliferation and promotes apoptosis of human hypertrophic scar fibroblasts in vitro. J Dermatol 41: 903-911, 2014.

8. Xiao YY, Fan PJ, Lei SR, Qi M and Yang XH: MiR-138/peroxisome proliferator-activated receptor $\beta$ signaling regulates human hypertrophic scar fibroblast proliferation and movement in vitro. J Dermatol 42: 485-495, 2015.

9. Wang X, Zhang Y, Jiang BH, Zhang Q, Zhou RP, Zhang L and Wang C: Study on the role of Hsa-miR-31-5p in hypertrophic scar formation and the mechanism. Exp Cell Res 361: 201-209, 2017.

10. Chen L, Li J, Li Q, Yan H, Zhou B, Gao Y and Li J: Non-coding RNAs: The new insight on hypertrophic Scar. J Cell Biochem 118: 1965-1968, 2017.

11. Hammond SM: An overview of microRNAs. Adv Drug Deliv Rev 87: 3-14, 2015.

12. Soifer HS, Rossi JJ and Saetrom P: MicroRNAs in disease and potential therapeutic applications. Mol Ther 15: 2070-2079, 2017.

13. Krol J, Loedige I and Filipowicz W: The widespread regulation of microRNA biogenesis, function and decay. Nat Rev Genet 11: 597-610, 2010.

14. O'Connell RM, Rao DS, Chaudhuri AA and Baltimore D: Physiological and pathological roles for microRNAs in the immune system. Nat Rev Immunol 10: 111-122, 2010.

15. Zhang G, Liu Z, Cui G, Wang X and Yang Z: MicroRNA-486-5p targeting PIM-1 suppresses cell proliferation in breast cancer cells. Tumour Biol 35: 11137-11145, 2014.

16. Liu C, Li M, Hu Y, Shi N, Yu H, Liu H and Lian H: miR-486-5p attenuates tumor growth and lymphangiogenesis by targeting neuropilin-2 in colorectal carcinoma. Onco Targets Ther 9: 2865-2871, 2016.

17. Peng Y, Dai Y, Hitchcock C, Yang X, Kassis ES, Liu L, Luo Z, Sun HL, Cui R, Wei H, et al: Insulin growth factor signaling is regulated by microRNA-486, an underexpressed microRNA in lung cancer. Proc Natl Acad Sci USA 110: 15043-15048, 2013.

18. Oh HK, Tan AL, Das K, Ooi CH, Deng NT, Tan IB, Beillard E, Lee J, Ramnarayanan K, Rha SY, et al: Genomic loss of miR-486 regulates tumor progression and the OLFM4 antiapoptotic factor in gastric cancer. Clin Cancer Res 17: 2657-2667, 2011. 
19. Ma X, Wei J, Zhang L, Deng D, Liu L, Mei X, He X and Tian J: miR-486-5p inhibits cell growth of papillary thyroid carcinoma by targeting fibrillin-1. Biomed Pharmacother 80: 220-226, 2016.

20. Tredget EE, Nedelec B, Scott PG and Ghahary A: Hypertrophic scars, keloids, and contractures. The cellular and molecular basis for therapy. Surg Clin North Am 77: 701-730, 1997.

21. Xie JL, Qi SH, Pan S, Xu YB, Li TZ, Liu XS and Liu P: Expression of Smad protein by normal skin fibroblasts and hypertrophic scar fibroblasts in response to transforming growth factor beta1. Dermatol Surg 34: 1216-1225, 2008.

22. Zhang ZF, Zhang YG, Hu DH, Shi JH, Liu JQ, Zhao ZT, Wang HT, Bai XZ, Cai WX, Zhu HY and Tang CW: Smad interacting protein 1 as a regulator of skin fibrosis in pathological scars. Burns 37: 665-672, 2011.

23. Yin L, Zhao X, Ji S, He C, Wang G, Tang C, Gu S and Yin C: The use of gene activated matrix to mediate effective SMAD2 gene silencing against hypertrophic scar. Biomaterials 35: 2488-2498, 2014.

24. Hu HH, Chen DQ, Wang YN, Feng YL, Cao G, Vaziri ND and Zhao YY: New insights into TGF- $\beta /$ Smad signaling in tissue fibrosis. Chem Biol Interact 292: 76-83, 2018.

25. Ji X, Wu B, Fan J, Han R, Luo C, Wang T, Yang J, Han L, Zhu B, Wei D, et al: The anti-fibrotic effects and mechanisms of MicroRNA-486-5p in pulmonary fibrosis. Sci Rep 5: 14131, 2015.

26. Liu B, Sun J, Lei X, Zhu Z, Pei C and Qin L: MicroRNA-486-5p suppresses TGF- $\beta 2$-induced proliferation, invasion and epithelial-mesenchymal transition of lens epithelial cells by targeting Smad2. J Biosci 42: 575-584, 2017.

27. Qi J, Liu Y, Hu K, Zhang Y, Wu Y and Zhang X: MicroRNA-26a inhibits hyperplastic scar formation by targeting Smad2. Exp Ther Med 15: 4332-4338, 2018.

28. Livak KJ and Schmittgen TD: Analysis of relative gene expression data using real-time quantitative PCR and the 2(-Delta Delta C(T)) method. Methods 25: 402-408, 2001.

29. Armour A, Scott PG and Tredget EE: Cellular and molecular pathology of HTS: Basis for treatment. Wound Repair Regen 15 (Suppl 1): S6-S17, 2007.

30. Schäfer $M$ and Werner S: Transcriptional control of wound repair. Annu Rev Cell Dev Biol 23: 69-92, 2007.
31. Kwan P, Hori K, Ding J and Tredget EE: Scar and contracture: Biological principles. Hand Clin 25: 511-528, 2009.

32. Babalola O, Mamalis A, Lev-Tov $\mathrm{H}$ and Jagdeo J: The role of microRNAs in skin fibrosis. Arch Dermatol Res 305: 763-776, 2013.

33. Yang Y, Ji C, Guo S, Su X, Zhao X, Zhang S, Liu G, Qiu X, Zhang Q, Guo H and Chen H: The miR-486-5p plays a causative role in prostate cancer through negative regulation of multiple tumor suppressor pathways. Oncotarget 8: 72835-72846, 2017.

34. Fu SJ, Chen J, Ji F, Ju WQ, Zhao Q, Chen MG, Guo ZY, Wu LW, Ma Y, Wang DP, et al: MiR-486-5p negatively regulates oncogenic NEK2 in hepatocellular carcinoma. Oncotarget 8: 52948-52959, 2017.

35. Youness RA, El-Tayebi HM, Assal RA, Hosny K, Esmat G and Abdelaziz AI: MicroRNA-486-5p enhances hepatocellular carcinoma tumor suppression through repression of IGF-1R and its downstream mTOR, STAT3 and c-Myc. Oncol Lett 12: 2567-2573, 2016

36. Viñas JL, Burger D, Zimpelmann J, Haneef R, Knoll W, Campbell P, Gutsol A, Carter A, Allan DS and Burns KD: Transfer of microRNA-486-5p from human endothelial colony forming cell-derived exosomes reduces ischemic kidney injury. Kidney Int 90: 1238-1250, 2016.

37. Eppert K, Scherer SW, Ozcelik H, Pirone R, Hoodless P, Kim H, Tsui LC, Bapat B, Gallinger S, Andrulis IL, et al: MADR2 maps to $18 \mathrm{q} 21$ and encodes a TGFbeta-regulated MAD-related protein that is functionally mutated in colorectal carcinoma. Cell 86: 543-552, 1996

38. Riggins GJ, Thiagalingam S, Rozenblum E, Weinstein CL, Kern SE, Hamilton SR, Willson JK, Markowitz SD, Kinzler KW and Vogelstein B: Mad-related genes in the human. Nat Genet 13: 347-349, 1996.

This work is licensed under a Creative Commons Attribution-NonCommercial-NoDerivatives 4.0 International (CC BY-NC-ND 4.0) License. 